\title{
COMPARATIVE ANALYSIS OF TYPE 3 AND TYPE 4 CASSAVA PEELING MACHINES
}

\author{
C. Nathan ${ }^{1,}$, J. Wadai ${ }^{2}$ and I. U. Haruna ${ }^{3}$

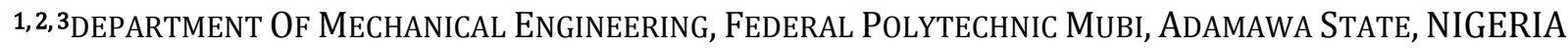 \\ E-mail addresses: ${ }^{1}$ chindapin@gmail.com, ${ }^{2}$ jwadai@yahoo.com, ${ }^{3}$ heldabuk@yahoo.com
}

\begin{abstract}
Cassava peeling has become the major problem of cassava processing worldwide. This is attributed to the irregularity in shape, size and thickness across different varieties of cassava tubers. The aim of this research work is to compare the peeling performance of type 3 cassava peeling machine with two (2) abrasive peeling tools and type 4 cassava peeling machine with four (4) abrasive peeling tools. The machines were evaluated at four (4) different speeds; (80rev/min, 90rev/min, 100rev/min, and 110rev/min) with 5HP electric motor. Cassava tubers of average mass of $0.72 \mathrm{~kg}, 0.74 \mathrm{~kg}, 0.76 \mathrm{~kg}, 0.78 \mathrm{~kg}$ and $0.80 \mathrm{~kg}$ were used for the experiment. The results of the properties evaluated for type 3 and type 4 peelers at $80 \mathrm{rev} / \mathrm{min}$ are; mass of peeled cassava (80\% and $86 \%$ ), mass of cassava peels (16\% and $18 \%$ ), mass of cassava flesh loss (2.06\% and $2.16 \%$ ), mass of unpeeled cassava ( $0.85 \%$ and $0.75 \%$ ), peeling efficiency (85\% and 90\%), mechanical damage (0.046 kg/kg and $0.065 \mathrm{~kg} / \mathrm{kg})$, throughput capacity (1141 kg/h and 1262kg/h) respectively. The performance of type 4 peeler was generally better than type 3 peeler with regards to properties evaluated, except for the percentage flesh loss and mechanical damage which were better with type 3 peeler.
\end{abstract}

Key words: Abrasive, Varieties, Throughput, Processing, Peeler.

\section{INTRODUCTION}

Cassava has become one of the most important crops that are required to be provided for both local consumption and export promotion. Apart from human consumption, cassava is also used for animal feed and alcohol production [1, 2]. Since 1930, Nigeria has surpassed Brazil as the world's leading producer of cassava with an estimated annual production of 26 million tons from an estimated area of 1.7 million hectares of land [3]. Other major producers of cassava are Congo DR, Thailand, Indonesia, China, Malaysia, Malawi, Togo, and Tanzania [4].

The demand for cassava products is on the increase and Government interest in cassava research is also increasing with strong emphasis on mechanization. This is because cassava processing is labor intensive and the qualities of processed items are below acceptable standard. Lack of mechanization is responsible for longer time in processing a given product [5]. Tours of institution in Nigeria reveal the near absence of an effective cassava peeling machine. Peeling is therefore carried out manually by women and children [5].

The processing pattern of cassava from the raw tuber after matured for harvesting involved: harvesting, prewashing, grating, pressing and frying [6]. Out of these six (6) work stations only pre-washing, grating, and pressing were well mechanized in Nigeria. Others: harvesting and peeling constitute the major problem of cassava processing, in some cases, especially when the cassava is being used for Animal feed, peeling may be unnecessary [7]. Cassava peeling has been practiced as far back as when cassava was discovered, but the instrument for peeling has evolved from stone and wooden flight into simple house hold knife. This makes peeling of a large quantity of cassava drudgery [8]. According to Igbeka [9], the cassava tuber has two layers. The outer layer called the periderm and the inner layer called the cortex.

The problem encountered in peeling cassava tuber arises from the fact that cassava tubers exhibits appreciable difference in weight, size and shape [10]. There are also difference in the properties of cassava peels which varies in thickness, texture, and strength of adhesion to the flesh [11]. Several attempts have been made at solving these problems which resulted to the development of various types of cassava peeling machines [12, 13]. Thus, it is difficult to design a cassava peeling machine capable of efficiently peeling all tubers due to wide difference in properties of roots from various sources. It was revealed that cassava peeling is still largely done manually [14]. This study is 
aimed at comparing the peeling performance of type 3 with type 4 cassava peeling machine. The study seeks an uncomplicated design to make it cost effective just like the cassava grinding machines.

\section{MATERIALS AND METHODS}

\subsection{Research Materials}

The cassava (Manihot esculenta) used for the experiment was acquired from the market in Iselu Market, Benin. Fifty samples of cassava tubers of average mass of $0.72 \mathrm{~kg}, 0.74 \mathrm{~kg}, 0.76 \mathrm{~kg}, 0.78 \mathrm{~kg}$, and $0.80 \mathrm{~kg}$, were selected and cut to a length of $180 \mathrm{~mm}$. Scale balance was used to measure the mass of cassava tubers before peeling, mass of the peeled cassava and the mass of the materials removed.

\subsection{Measuring Tools and Instruments}

Variety of tools and instruments were used to carry out different measurements on the root tubers. A tape rule was used to measure the length of cassava tubers while the diameter of the cassava tubers were measured using a pair of Vernier caliper. The mass of cassava tubers before and after peeling and mass of cassava peels removed were measured with a scale balance. The time of operation was measured using a stop watch while the residual cassava peels were removed by a knife.

\subsection{Description of the Machines (Type 3 and Type 4)}

Two different machines were used for the analysis. The type 3 cassava peeling machine having Two abrasive peeling shafts of diameter $60 \mathrm{~mm}$ designed on a stainless steel and type 4 cassava peeling machine developed with four abrasive peeling shafts of diameter $60 \mathrm{~mm}$ designed on a stainless steel. These machines were designed and fabricated at the Department of Production Engineering, University of Benin, Benin city, Edo State, Nigeria. The peeling processes were carried out simultaneously with machines type 3 and type 4 using the same materials and method.

\subsubsection{Description of Type 3 Cassava Peeling Machine}

The peeling chamber and the peeling tool are mounted on a supporting frame. The peeling tool is the rotating cylindrical shaft upon which abrasive surfaces are designed on a stainless steel and folded round the shaft and permanently welded. A screw conveyor was design and developed to pass through the peeling chamber to the chute. Both the peeling shaft and the conveyor shaft were driven by a 5HP electric motor. A belt and pulley mechanism was used to transfer the motion from the electric motor to the peeling shaft and to the conveyor shaft. The hopper was designed such that cut cassava tubers placed into the machine lie horizontally on the conveyor shaft. The peeling chamber can accommodate five cassava tubers of average mass of $0.70 \mathrm{~kg}$ to average mass of $80 \mathrm{~kg}$ at a time. The peeling abrasives peel the cassava tubers as the cassava tubers are moving and rotating on the conveyor shaft to the discharge chute. Little clearance was left between the peeling shafts and the conveyor shaft that will not allow cassava tubers to drop through but will be large enough to allow the tuber peels to fall off and finds its way to the discharge chute. A guard is placed to prevent direct contact between the operator and the fast rotating peeling spikes. The cut away and pictorial views of type 3 cassava peeling machine are shown in Figures 1 and 2 respectively.

\subsubsection{Description of Type 4 Cassava Peeling Machine}

The design and development of type 4 cassava peeling machine is similar to type 3 cassava peeling machine. The difference between the two cassava peelers is the number of peeling shafts. Type 3 cassava peeling machine uses two peeling shafts as the peeling tool and type 4 cassava peeling machine uses four (4) peeling shafts as the peeling tool. Their mode of operation is the same. And all the materials used for type 3 cassava peeling machine were also used for type 4 cassava peeling machine. The cut away and pictorial views of type 4 cassava peeling machine are shown in Figures 3 and 4 respectively.

\subsection{Determination of Tuber Size}

Cassava tubers used for the experiment were categorized into five different classes based on average mass of $0.72 \mathrm{~kg}, 0.74 \mathrm{~kg}, 0.76 \mathrm{~kg}, 0.78 \mathrm{~kg}$, and $0.80 \mathrm{~kg}$. And the tubers were cut into length of $180 \mathrm{~mm}$ each.

\subsection{Performance Evaluation of the Machines}

During the peeling operation, some parts of the cassava may remain unpeeled due to irregularity of cassava tuber shapes or due to shorter peeling time. The machine operational variables such as peeling efficiency, tuber flesh losses, peel retention and peeling time were determined and considered as dependant variables while crop and machine variables such as tuber size, mass and machine speed were treated as independent variables.

\subsection{Operation}

The cassava tubers as obtained from the market with average mass of $0.72 \mathrm{~kg} 0.74 \mathrm{~kg}, 0.76 \mathrm{~kg}, 0.78 \mathrm{~kg}$, and $0.80 \mathrm{~kg}$ were used for the experiment. Cassava tubers 
were fed into the peeler, and on dropping on the screw conveyor, the conveyor conveyed the cassava to the chute. The peeling abrasives peeled the cassava as the cassava tubers were passing to the chute on the screw conveyor. Scale balance was used to measure the mass of the materials removed.

\subsection{Theoretical Method}

Equations 1 to 8 were used for the performance analysis of the cassava peeling machines [15].

$$
\begin{aligned}
& \% \text { Mass of peeled cassava }=\frac{M_{p}}{M_{u}} \times 100 \% \\
& \% \text { Mass of peels }=\frac{M_{p l s}}{M_{u}} \times 100 \% \\
& \% \text { Mass of flesh loss }=\frac{M_{f}}{M_{t f}} \times 100 \% \\
& \% \text { of unpeeled }=\frac{M_{u p}}{M_{u}} \times 100 \% \\
& \text { Proportion mass of peels, } \mathrm{P}=\frac{M_{p}}{M_{u}} \times 100 \% \\
& \text { Peeling efficiency, } \mathrm{n}=\frac{M_{p l s}}{M_{u p}+M_{p l s}} \times 100 \% \\
& \text { Throughput capacity, } T_{C}=\frac{M_{t}}{T} \\
& \text { Mechanical damage, } \lambda=\frac{M_{f}}{M_{p}+M_{f}}
\end{aligned}
$$

In (1) to (8), $M_{t}$ is the mass of cassava fed into the machine in $\mathrm{kg}, \mathrm{n}$ the peeling efficiency in percentage (\%), $\lambda$ the mechanical damage in $\mathrm{kg} / \mathrm{kg}, T_{C}$ the throughput capacity in $\mathrm{kg} / \mathrm{h}, M_{t f}$ is the total mass of flesh tubers in $\mathrm{kg} . \mathrm{M}_{\mathrm{u}}$ is the mass of unpeeled cassava in (kg), $M_{p l s}$ is the mass of cassava peels (peeling) collected at the outlet of the machine in $\mathrm{kg}, \mathrm{M}_{\text {up }}$ is the mass of cassava peels (peeling) removed by hand after machine peeling in $\mathrm{kg}, \mathrm{M}_{\mathrm{f}}$ is the mass of cassava flesh loss which was removed along with the peels by the machine in $\mathrm{kg}, M_{p}$ is the mass of completely peeled cassava tuber in $\mathrm{kg}, \mathrm{P}$ is the proportion mass of cassava peel (peeling) $=\mathrm{M}_{\mathrm{p}} / \mathrm{M}_{\mathrm{u}} \%$. L is the length of the cassava tuber in $\mathrm{mm}$ and $\mathrm{T}$ is the time taken for cassava and its peels (peeling) to completely leave the machine in seconds.

\section{RESULTS AND DISCUSSION}

Tables 1 and 2 shows the results of the trial runs performed on machine type 3 and machine type 4 and plotted in figures 5 to 12 . Figure 5 shows that, the mass of peeled cassava was highest with a value of $80 \mathrm{~kg}$ at $80 \mathrm{rev} / \mathrm{min}$ speed of the peeling shaft and lowest of $68 \mathrm{~kg}$ at $110 \mathrm{rev} / \mathrm{min}$ for machine type 3 . For machine type 4, the highest mass of peeled cassava was recorded as $85 \mathrm{~kg}$ at $80 \mathrm{rev} / \mathrm{min}$ and lowest value of $72 \mathrm{~kg}$ at $110 \mathrm{rev} / \mathrm{min}$. This indicates that the mass of peeled cassava increases with decrease in speed of the peeling shaft and vice versa for both machine type 3 and machine type 4. It was concluded that good peeling was obtained at low speed of the peeling shaft.

Figure 6 shows the graph of mass of cassava peels against the speed of the peeling shaft for machine type 3 and type 4 . For machine type 3, the mass of peels was highest at $80 \mathrm{rev} / \mathrm{min}$ with a value of $13 \%$ and lowest with a value of $11.5 \%$ at $110 \mathrm{rev} / \mathrm{min}$. For machine type 4 , the mass of peels was highest with value of $13.56 \%$ at $80 \mathrm{rev} / \mathrm{min}$ and lowest of $12.00 \%$ at $110 \mathrm{rev} / \mathrm{min}$ speed of the peeling shaft.

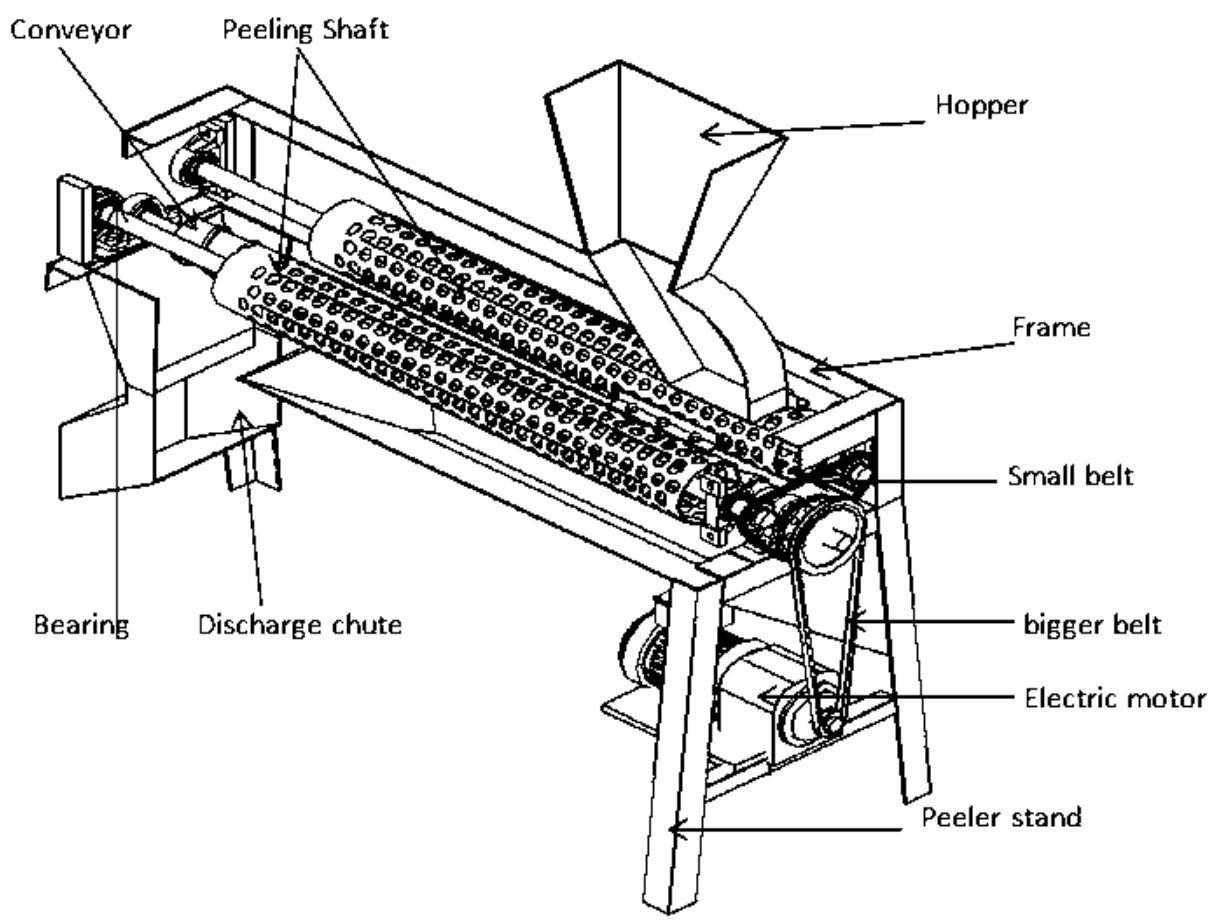

Figure 1: Cut-away of type 3 cassava peeling machine 


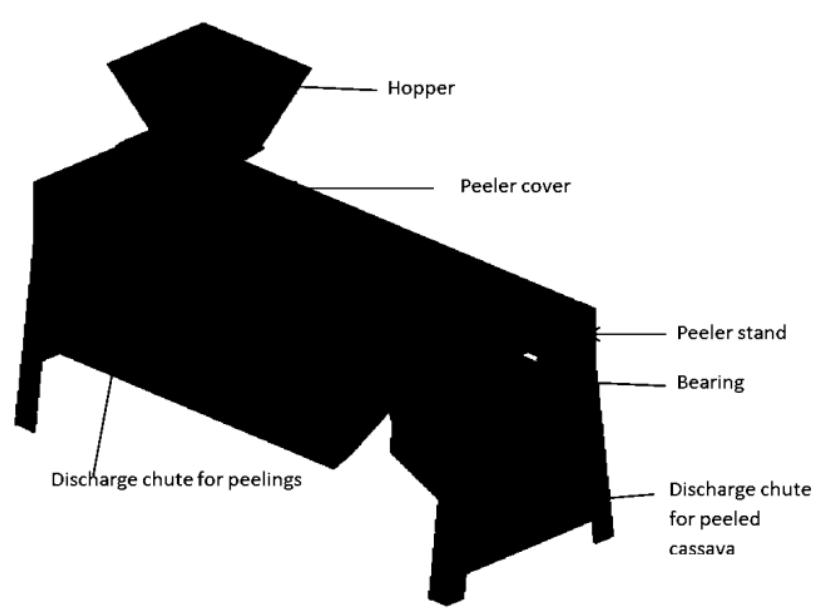

Figure 2: Pictorial view of type 3 cassava peeling machine

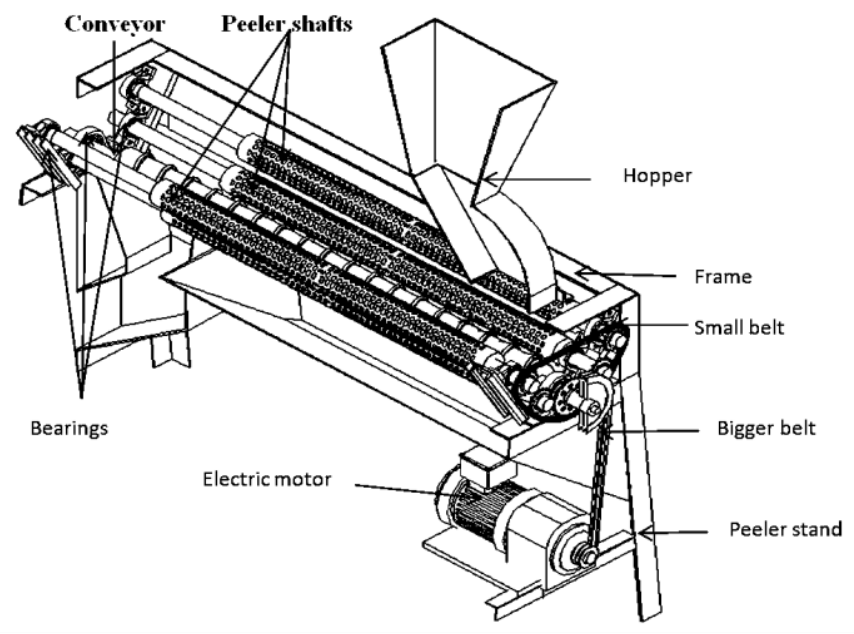

Figure 3: Cut-away of type 4 cassava peeling machine

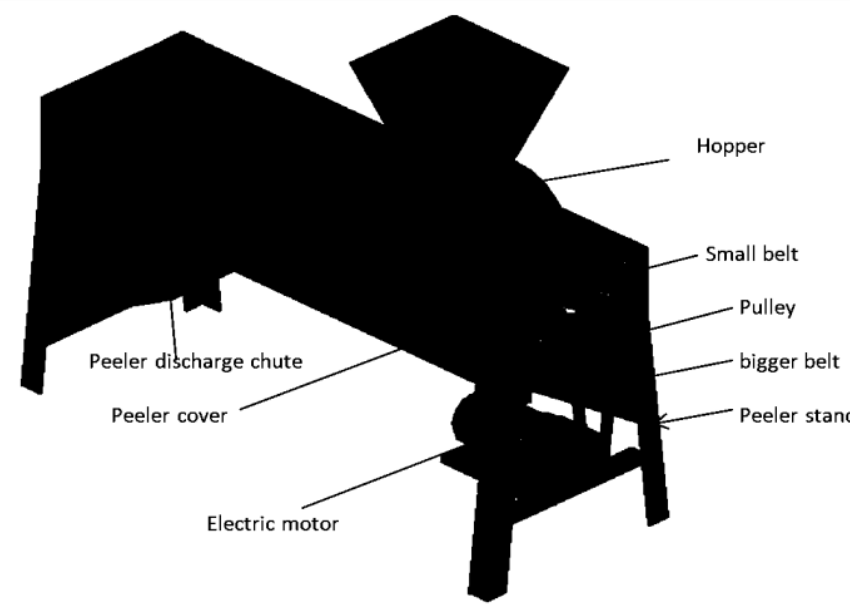

Figure 4: Pictorial view of type 4 cassava peeling machine

The reason for high mass of peels at $80 \mathrm{rev} / \mathrm{min}$ for both type 3 and type 4 is that at low speed good peeling was obtained resulting in more percentage mass of cassava peels. Figure 7 shows the graph of mass of cassava flesh loss against the speed of the peeling shaft for machine type 3 and machine type 4 . For machine type 3 , the highest mass of flesh loss was obtained as $9.32 \%$ at $110 \mathrm{rev} / \mathrm{min}$ and lowest of $0.80 \%$ at $80 \mathrm{rev} / \mathrm{min}$ speed of the peeling shaft. For machine type 4 , the highest mass of cassava flesh loss was obtained as $10 \%$ at $110 \mathrm{rev} / \mathrm{min}$ and lowest of $0.85 \%$ at $80 \mathrm{rev} / \mathrm{min}$ speed of the peeling shaft. The reason for high flesh loss at $110 \mathrm{rev} / \mathrm{min}$ is, the cassava tubers move with high speed and hit the peeling abrasives resulting in flesh loss.

Figure 8 shows the graph of unpeeled cassava against the speed of the peeling shaft for machine type 3 and machine type 4 . For type 3 peeler, the mass of unpeeled cassava was highest at $110 \mathrm{rev} / \mathrm{min}$ with a value of $9.32 \%$ and lowest at $80 \mathrm{rev} / \mathrm{min}$ with value of $0.90 \%$. For machine type 4 , the highest mass of unpeeled was obtained as $8.10 \%$ at $110 \mathrm{rev} / \mathrm{min}$ and lowest of $0.80 \%$ at $80 \mathrm{rev} / \mathrm{min}$ speed of the peeling shaft. The high mass of unpeeled at $110 \mathrm{rev} / \mathrm{min}$ for both the peelers can be explained as follows: At high speed of the peeling shaft, the cassava tubers move with high speed on the conveyor shaft and may pass the peeling abrasives without good contact with the abrasive surfaces. Good peeling was obtained at lower speeds of the peeling shaft.

Figure 9 shows the graph of proportion mass of cassava peels against the speed of the peeling shaft for machine type 3 and machine type 4 . For machine type 3, the proportion mass of cassava peels was highest at $80 \mathrm{rev} / \mathrm{min}$ with a value of $0.86 \mathrm{~kg}$, and lowest at $110 \mathrm{rev} / \mathrm{min}$ with a value of $0.71 \%$. For machine type 4 , the proportion mass of cassava peels was highest at $80 \mathrm{rev} / \mathrm{min}$ with a value of $0.89 \%$ and lowest at $110 \mathrm{rev} / \mathrm{min}$ with a value of $0.74 \%$. The high proportion mass of peels at $80 \mathrm{rev} / \mathrm{min}$ for both the peelers is, good peeling was obtained at low speed resulting in more proportion mass of cassava peels. For both the peelers, the proportion mass of cassava peels increases with decrease in speed of the peeling shaft.

Figure 10 shows the graph of peeling efficiency against the speed of the peeling shaft for machine type 3 and type 4 cassava peeling machines. For machine type 3, the peeling efficiency was highest at $80 \mathrm{rev} / \mathrm{min}$ with a value of $75 \%$ and lowest at $110 \mathrm{rev} / \mathrm{min}$ with a value of $60 \%$. For machine type 4 , the highest peeling efficiency was obtained as $80 \%$ at $80 \mathrm{rev} / \mathrm{min}$ and lowest of $65 \%$ at $110 \mathrm{rev} / \mathrm{min}$ speed of the peeling shaft. The peeling efficiency at $80 \mathrm{rev} / \mathrm{min}$ for both the peelers was good, because good peeling was obtained at low speed of the peeling shaft.

Figure 11 shows the graph of mechanical damage against the speed of the peeling shaft for machine type 
3 and type 4. As the speed of the peeling shaft increases, mechanical damage also increases for both type 3 and type 4 peelers. For machine type 3, the highest mechanical damage was recorded as $0.125 \%$ at $110 \mathrm{rev} / \mathrm{min}$ and lowest of $0.062 \%$ at $80 \mathrm{rev} / \mathrm{min}$. For machine type 4 , the highest mechanical damage was recorded as $0.145 \%$ at $110 \mathrm{rev} / \mathrm{min}$ and lowest of $0.073 \%$ at $80 \mathrm{rev} / \mathrm{min}$. This can be attributed to the fact that as the speed of the peeling shaft increases the speed with which the cassava tubers are conveyed on the peeling shaft increases and hit the abrasive surfaces which result in loss of flesh of the cassava tubers.

Figure 12 shows the graph of throughput capacity against the speed of the peeling shaft for both the peelers. For type 3 peeler, the throughput capacity was highest at $110 \mathrm{rev} / \mathrm{min}$ with a value of $1150 \mathrm{~kg} / \mathrm{h}$ and lowest at $80 \mathrm{rev} / \mathrm{min}$ with the value of $680 \mathrm{~kg} / \mathrm{h}$. For type 4 peeler the highest throughput capacity was obtained as $1250 \mathrm{~kg} / \mathrm{h}$ at $110 \mathrm{rev} / \mathrm{min}$ and lowest of $710 \mathrm{~kg} / \mathrm{h}$ at $80 \mathrm{rev} / \mathrm{min}$ speed of the peeling shaft. For both type 3 and type 4 peelers, the throughput capacity increases with increase in speed of the peeling shaft and decreases with decrease in speed of the peeling shaft.

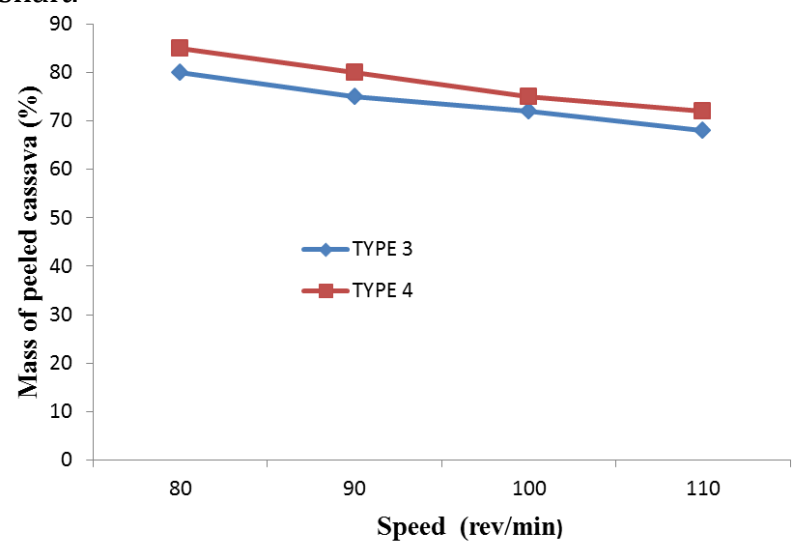

Fig. 5: Graph of Mass of Peeled Cassava against the Speed of the Peeling Shaft (Type 3 and 4)

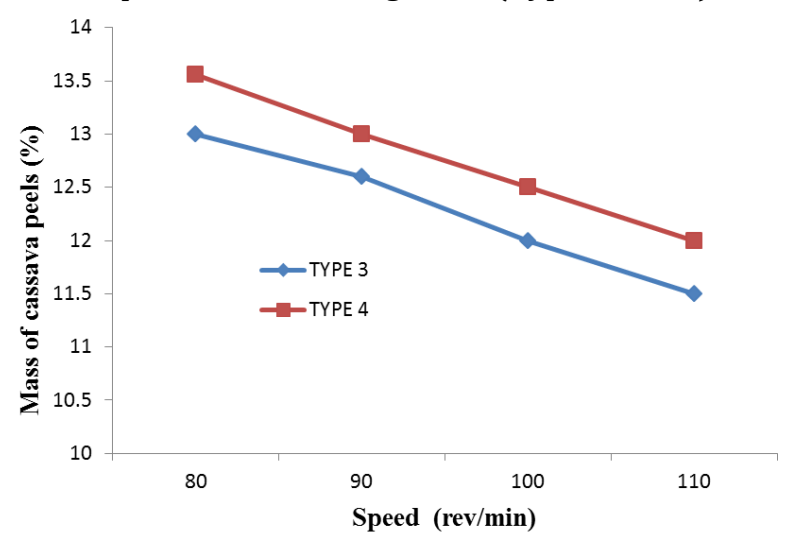

Fig. 6: Graph of Mass of Cassava peels against the Speed of the Peeling Shaft (Type 3 and 4)

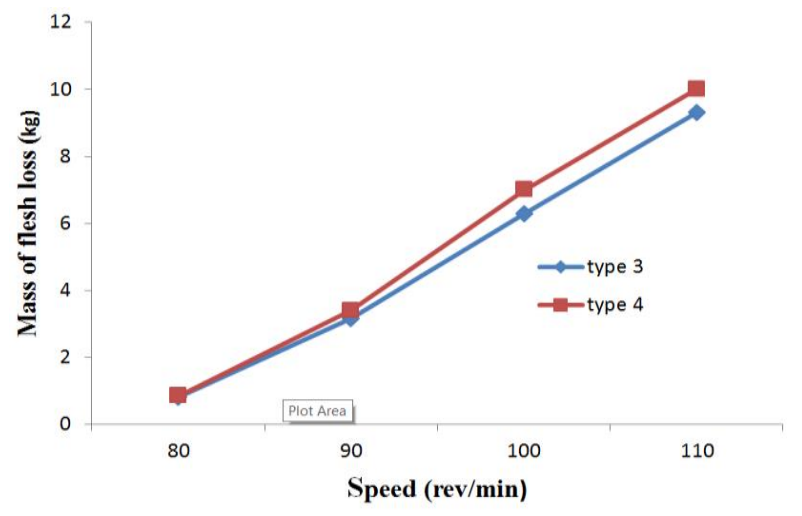

Fig. 7 Graph of Mass of cassava flesh loss against the Speed of the Peeling Shaft (Type 3 and 4)

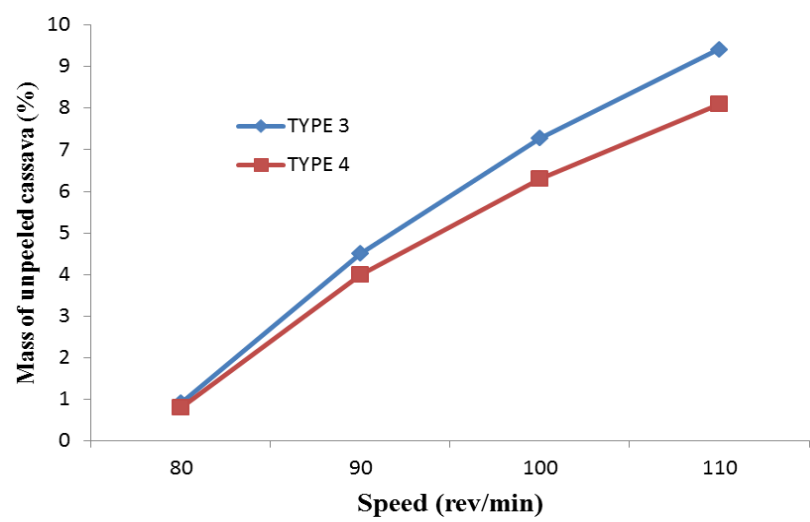

Fig. 8 Graph of Mass of unpeeled Cassava against the Speed of the Peeling Shaft (Type 3 and 4)

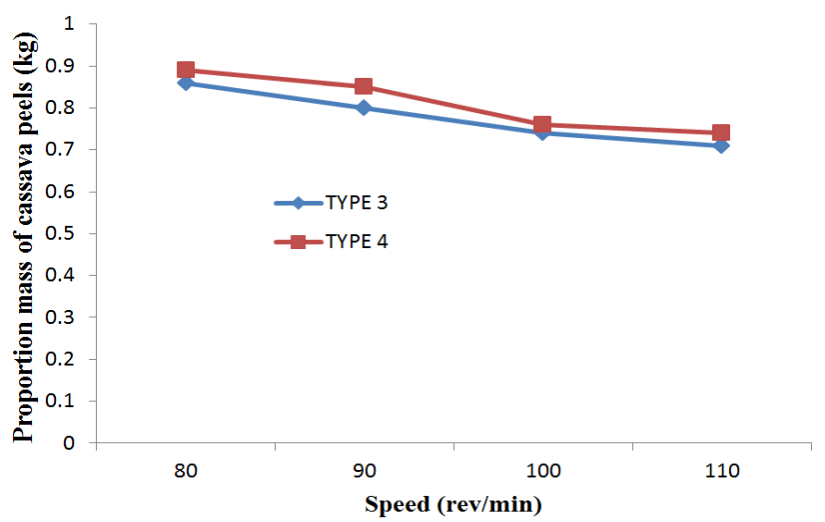

Fig. 9: Graph of Proportion Mass of Cassava Peels against the Speed of the Peeling Shaft (Type 3 and 4)

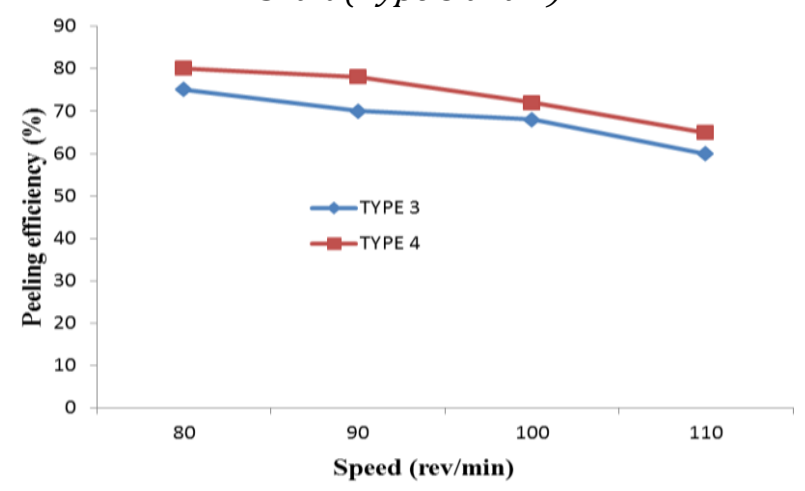

Fig. 10: Graph of Peeling Efficiency against the Speed of the Peeling Shaft (Type 3 and 4)

Vol. 36, No. 4, October 2017 


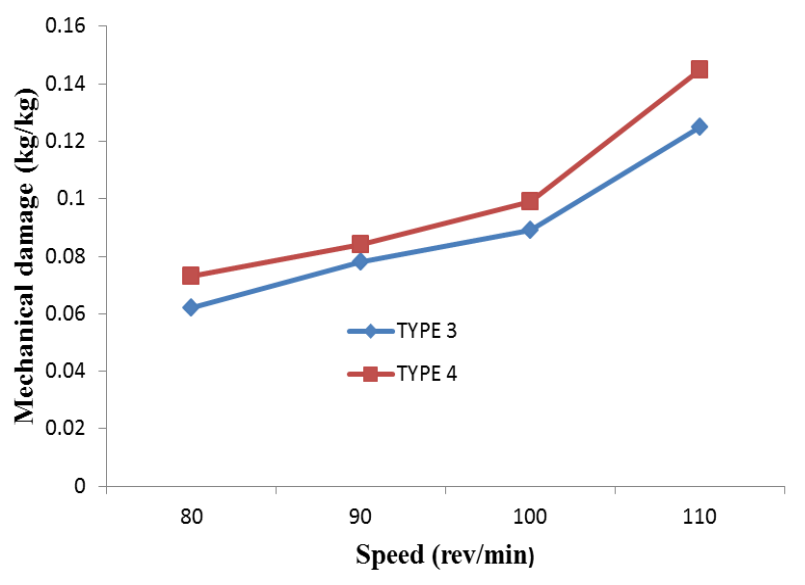

Fig. 11: Graph of Mechanical Damage against the Speed of the Peeling Shaft (Type 3 and 4)

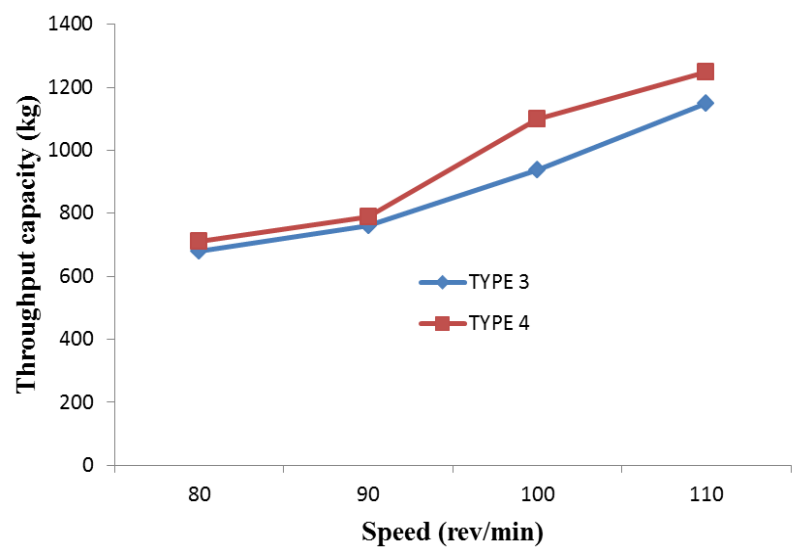

Fig. 12: Graph of Throughput Capacity against the

Speed of the Peeling Shaft (Type 3 and 4)

\section{CONCLUSION AND RECOMMENDATIONS}

\subsection{Conclusion}

From the two cassava peeling machines developed for this study, the type 3 cassava peeling machine developed with two abrasives shafts as the peeling tool and the type 4, cassava peeling machine developed with four abrasive shafts as the peeling tools. Type 4 cassava peeling machine gave better values of average mass of peeled cassava tubers, average mass of cassava peels, proportion mass of cassava peels, peeling efficiency, and throughput capacity than type 3 cassava peeling machine. The average mass of flesh loss, average mass of unpeeled cassava and mechanical damage were recorded highest with machine type 4 compared to machine type 3 . Machine type 4 gave better peeling performance than machine type 3 .

\subsection{Recommendations}

1. Water should be employed in the design of the cassava peeling machine to clean the abrasive surfaces to minimize the clogging of the abrasive surfaces.

2. Two different tools can be used on the same peeling machine for good peeling.

Table 1: Results of the Trial Runs Performed at different Speed of the Peeling Shaft (Type 3 peeler)

\begin{tabular}{ccccccccc}
\hline $\begin{array}{c}\text { Speed } \\
\text { rev/min }\end{array}$ & $\begin{array}{c}\text { Average } \\
\text { mass of } \\
\text { peeled } \\
\text { cassava } \\
(\%)\end{array}$ & $\begin{array}{c}\text { Average } \\
\text { mass of } \\
\text { cassava } \\
\text { peels }(\%)\end{array}$ & $\begin{array}{c}\text { Average } \\
\text { mass of } \\
\text { cassava } \\
\text { flesh loss } \\
(\%)\end{array}$ & $\begin{array}{c}\text { Average } \\
\text { mass of } \\
\text { unpeeled } \\
\text { Cassava }(\%)\end{array}$ & $\begin{array}{c}\text { Proportion } \\
\text { mass of } \\
\text { cassava peels } \\
(\mathrm{kg})\end{array}$ & $\begin{array}{c}\text { Peeling } \\
\text { efficiency } \\
(\%)\end{array}$ & $\begin{array}{c}\text { Mechanical } \\
\text { damage } \\
(\mathrm{kg} / \mathrm{kg})\end{array}$ & $\begin{array}{c}\text { Throughput } \\
\text { capacity }(\mathrm{kg} / \mathrm{h})\end{array}$ \\
\hline 80 & 80 & 13.0 & 0.80 & 0.90 & 0.86 & 75 & 0.062 & 680 \\
90 & 75 & 12.6 & 3.15 & 4.50 & 0.80 & 70 & 0.078 & 760 \\
100 & 72 & 12.0 & 6.30 & 7.28 & 074 & 68 & 0.089 & 937 \\
110 & 68 & 11.5 & 9.32 & 9.42 & 0.71 & 60 & 0.125 & 1150 \\
\hline
\end{tabular}

Table 2: Results of the Trial Runs Performed at different Speed of the Peeling Shaft (Type 4 peeler)

\begin{tabular}{ccccccccc}
\hline $\begin{array}{c}\text { Speed } \\
\text { rev/min }\end{array}$ & $\begin{array}{c}\text { Average } \\
\text { mass of } \\
\text { peeled } \\
\text { cassava } \\
(\%)\end{array}$ & $\begin{array}{c}\text { Average } \\
\text { Mass of } \\
\text { cassava } \\
\text { peels (\%) }\end{array}$ & $\begin{array}{c}\text { Average } \\
\text { mass of } \\
\text { cassava } \\
\text { flesh } \\
\text { loss }(\%)\end{array}$ & $\begin{array}{c}\text { Average } \\
\text { mass of } \\
\text { unpeeled } \\
\text { cassava }(\%)\end{array}$ & $\begin{array}{c}\text { Proportion } \\
\text { mass of } \\
\text { cassava peels } \\
(\mathrm{kg})\end{array}$ & $\begin{array}{c}\text { Peeling } \\
\text { efficiency } \\
(\%)\end{array}$ & $\begin{array}{c}\text { Mechanical } \\
\text { damage } \\
(\mathrm{kg} / \mathrm{kg})\end{array}$ & $\begin{array}{c}\text { Throughput } \\
\text { capacity } \\
(\mathrm{kg} / \mathrm{h})\end{array}$ \\
\hline 80 & 85 & 13.56 & 0.85 & 0.80 & 0.89 & 80 & 0.073 & 710 \\
90 & 80 & 13.00 & 3.40 & 4.00 & 0.85 & 78 & 0.084 & 790 \\
100 & 75 & 12.50 & 7.00 & 7.30 & 076 & 72 & 0.099 & 1000 \\
110 & 72 & 12.00 & 10.00 & 8.10 & 0.74 & 65 & 0.145 & 1250 \\
\hline
\end{tabular}




\section{REFERENCES}

[1] Onwueme, I. C. and Dsinha "Field Crop Production in Tropical Africa" Journal of Food, Agricultural and Environment, Vol. 6: 1999, Pp. 4-9.

[2] Onyenwoke, C. A and Simonyan, K. J "Cassava Post Harvest Processing and Storage in Nigeria" African Journal of Agricultural Research in Cassava Post Harvest Processing and Storage in Nigeria Vol. 9 (53): 2004, Pp. 3853-3863.

[3] FAO (1999). Accessed 15 January, 2015, from www.fao.org

[4] Odigboh, E. U. "A Cassava Peeling Machine Development, Design and Construction" Journal of Agric. Engineering Research, 21, 1976, Pp. 361369.

[5] Odigboh, E. U. "Cassava Production, Processing and Utilization" In: Handbook of Tropical Foods, New York: Mercel Decker Pub. Inc. 1983, Pp. 145-200.

[6] Davies, G. V. and Edoko U. K. (2014): Comparative Analysis of Type 1 and Type 2 Cassava Peeling Machine. International Journal of Agricultural Science and Innovations 6 (9), 2014, Pp. 58-73.

[7] FAO (2011). Accessed 15 January, 2015, from www.fao.org

[8] Oluwole, 0. O and Adio, M. O "Design and Construction of a Batch Cassava Peeling Machine" Journal of Mechanical Engineering and Automation 3(1), 2013, Pp. 16-21.

[9] Igbeka, J.C. "Mechanization of Cassava Tuber Peeling" Prac. Int. Symp. Mechanization of Harvesting and Subsequent Processing of Agricultural Products in Tropical Africa and the Manufacturing of Relevant Agricultural Implements, Younde Cameroun, 11-15 February, 1985.
[10] Adetan, A. D., Adekoya, I.O., Aluko, O. I. and Makanjuola, G. A. "An Experimental Mechanical Cassava Tuber Peeling Machine" Journal of Engineering. 59: 2005, Pp. 349-353.

[11] Olukunle, O. J., and Ademosun, O. C “Development of a Double Action Self-fed Cassava Peeling Machine" Journal of Food, Agricultural and Environment, Vol. 4: 2006, Pp. 3-4.

[12] Agbetoye, L. A.S, and Ademosun, O. C; Ogunlowo, A, S; Olukunle, O. J; Fapatu, O. P., and Adesina, A. "Developing Indigenous Machinery for Cassava Processing and Fruit Juice in Nigeria" In Proceedings of the first International Conference on Advances in Engineering and Technology, Entebbe, Uganda $16^{\text {th }}-19^{\text {th }}$ July, 2006, 375-384, Elsevier Publication Limited

[13] Ezekwe, G. 0. "A Future for Achieving a Constant Depth of Peel in the Mechanical Peeling of Cassava" Nigerian Journal of Engineering 1 (3): 1976, Pp. 174-181.

[14] Odigboh, E. U. "A Cassava Peeling Machine Development, Design and Construction" Journal of Agric. Engineering Research, 21, 1976, pp. 361369.

[15] Ariavie, G. O and Ohwovoriole, E. N "Improved Ohwovorioles Rotary Cassava Tuber Peeling Machine" Nigerian Journal of Engineering Research and Development 1(2): 2002, pp. 61-63

[16] Olukunle, O. J. and Jimoh, M. O "Comparative Analysis and Performance Evaluation of three cassava Peeling Machines" International Research Journal of Engineering Science, Technology and Innovation Vol. 1(4), July 2012. pp. 94-102. 